\title{
Map-based interaction for inputting in Mobile phones
}

\author{
Atish Patel \\ IDC, IIT Bombay. \\ Mumbai, India. \\ atishpatel06@gmail.com
}

\author{
Ishneet Grover \\ IDC, IIT Bombay. \\ Mumbai, India. \\ ishneetgrover@gmail.com
}

\begin{abstract}
The paper is about unique Map-based input mechanism for source and destination while booking Indian Railways ticket. This mechanism came as one of the strong alternative solution, in design project on "Ticketing for Indian Railways on Mobile Phone". Targeted to users in small towns, the aim project was to come up with solution which could bridge the commuting gap between the user and existing mobile internet application, which are difficult to use. Considering the mid-range phone which they possess, semi-literacy levels and difficulty in typing text using number pad; the proposed solution requires minimum textual input. Proposed Map-based solution uses number pad navigation method. The number pad on mobile phones is mapped with the Map of India plotted with rail stations and rail routes. Users have to select the position of their station and navigate to the required station for booking ticket. Learnability of this Map-based inputting method was found to be easy and fast compared to text inputting method.
\end{abstract}

Mobile based input methods, Digital divide, Mobile phone, Mobiles application for Rural, Mobile phone in India, Indian Railway ticketing, $m$ Commerce.

\section{INTRODUCTION}

Today India has 471.7 million mobile phone users out of which 57.8 million users have internet capability on it. [1] However many more poses basic mid-range mobile phones which can have internet capability on it. So, these basic phone users who have facility and infrastructure to use internet are still void of it because of inability to use phone device and conventional ways of interaction with mobile applications. If there are internet based applications and services which can be used by these kind of people to do their basic jobs done like small daily money transactions, finding information related to daily activities like farming, vegetable prices, quick medical advice, finding daily job opportunities; etc. these people will quickly subscribe for these kind of internet based services. Since this will be easy and very affordable way of accessing these kind of information and services. Also, today largest sections of society who do not possess Mobile Phones belong to people who are illiterate and semi-literate. Providing this kind of capability can drastically increase penetration of Mobile phones and internet based capabilities to great extent and brings a great change in their life [2]. Main aim of project was to make this group of people use the capabilities of internet.

Indian Railways is one of the most frequently required services by people in India. Many people migrate from small villages to towns for employment. Some travel back once years to their native places while some very frequently or daily.
Also, for Indian middle class and lower class people Indian Railways is the most affordable and popular means of travel. There are many reasons besides affordability like easy access to interior parts of Indian villages and towns, fast and safe mode of travel compared to road ways, etc. So ticketing for Indian Railways was chosen as a medium to achieve this aim. Today more than 18 million people [3] travel daily in Indian Railways out of which only 0.22 million use internet at their home for doing it [4]. So, the main goal was to enable basic mid-range phone user to book ticket using internet which can drastically increase the number of people booking ticket using internet.

\section{CHALLENGES INPUTTING SOURCE AND DESTINATION STATION:}

Entering Source/Destination of Indian Railways is difficult when it comes to inputting it on Mobile Phone. Major reasons for this are diverse and complex nature of both people and system;

There are nearly 7000 to 8000 stations in India out of which users can book tickets for 3467 station; [5] so, many times even incremental search results give long list of station. For e.g. when we type 'BAN' letters in input text field it still leaves us with 36 stations in the filtered list. Whereas to type in 'BAN' we have to do 5 presses using mid-range number pad based mobile phones interactions.

Many times people from different regions know same station by different names e.g. 'Mumbai' is known as Bambai or Bombay, 'Vadodara' is also 
known as Baroda, 'Delhi' is also called as Dilli and 'Pune' called as Poona or Poone etc. There are many similar sounding stations e.g. 'Anand Junction' in Gujarat state, 'Anand Nagar' in Andra Padesh, 'Anand Vihar' in West Bengal, etc. causing confusion.

Names of many stations are more than 10 alphabets which may consist of single name or more than two words combined e.g. 'Coimbatore North Junction', 'Visakhapatnam Junction', 'Trivandrum Pettah', etc. which are one of the major stations. Due to these reasons people often make spelling mistakes while inputting station names.

2001 Census data indicates that 45\% (468 million) people in India are illiterate out of if $76 \%$ ( 771 million) people have not studied beyond the primary school. [6] Majority of target users are nontech savvy and semi-literate.

In addition to this it is also found that majority of these kinds of people are not able to use basic functionalities of phone like sms, contact book, etc [8]. So, these are some of the things which show these people are not comfortable with text inputting and when it comes to mobile phones and that too using number pad difficultly increases to great extent.

Audio based inputting by Speech recognition was explored as one of the option for solving this problem, many issues were found which stopped from taking up this as final solution. There are 22 major languages spoken in India and over 1600 regional dialects. Even though Hindi is the official language, many people in India do not speak it at all. Hindi is spoken by about half the population, mostly in North India. Most languages have their own script. Some of the major languages are Hindi, English, Assamese, Bengali, Gujarati, Kannada, Kashmiri, Malayalam, Marathi, Oriya, Punjabi, Sanskrit, Tamil, Telugu, Urdu, etc. [7].

Also, this is the reason why the pronunciation of station names may drastically differ for people using different dialects. In addition to this there is always a personal way of speaking which will add to the delta in pronunciation, especially when it comes to people who are illiterate, semi-literate and belonging to small towns and villages delta will be large.

It was also found while doing competitive products study that IVRS based services were not liked to great extent, because of reasons like unavoidable options which needs to be heard, repeating behaviour of menus options prompted, easily prone to mistakes, etc.

\section{PROPOSED MAP-BASED SOLUTION FOR INPUTTING SOURCE AND DESTINATION:}

Map of India divided into $3 \times 3$ grids and mapped onto the number pad of mobile phone is used as inputting Source/Destination mechanism.

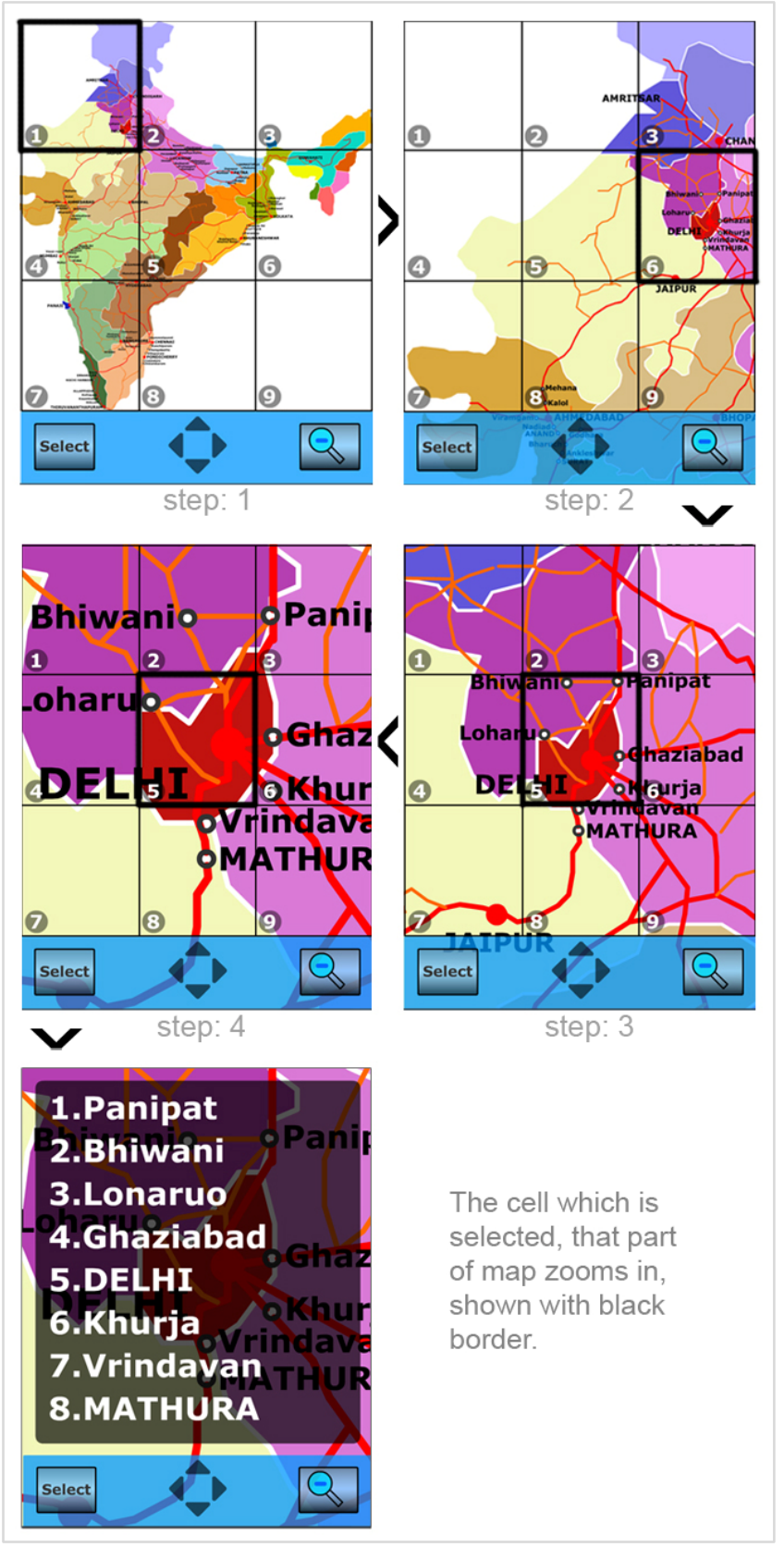

Figure 1: Map-based Interaction flow

In order to assist user in navigation, information is displayed on the map that evolves and gets detailed with every zoom in. In first level only the map with the state border and their capital cities marked are displayed. As user zooms in at second level name of state capital and major cities appear with rail routes. 
On selection of required cell where the station is, the cell zooms in till the stations of only selected cell appear on whole screen with similar grid over laid on it. User keeps zooming in the Map till the required station appears in the list view. At third zoom level all the stations appear with major cities in bold, at fourth zoom level user can easily read all the names of the station and when selects to zoom in, all the stations present in the map form a list which are now only number mapped.

Navigation and selection of required cell is done with number pad mapped keys, and centre of joystick key or key with 'Select' label is used to select the required cell.

In this navigation user can select any station using just four key presses. The density of stations at different places may vary. In most of the cases we can handle it with 4 level of zoom in. If the density of stations exceeds a $5^{\text {th }}$ level of zoom can be introduced or if, the density of stations is less it can be handled by 3 level of zoom in.

\section{USER STUDY:}

Majority of people booking ticket by Indian Railways are people who travel between their native place and the town where they work. Some travel frequently like once or twice a week, whereas some people travel on yearly bases. Sometime elderly people try to book their tickets through their children. People try to locate their station in the state to which their station belong and/or by some junction or major station nearest to their station.

There are comparatively small numbers of cases found during study when people were about to travel new place. It was found before travelling to any new place or booking their tickets, people try to find out information like where is the place situated, in which state or which is the major station near to destination station, etc. This gives them some idea of location to the station where they are travelling.

Some people also stated that they have rough idea of the location of their native places and if they are shown map they will be able to figure out where exactly it is.

\section{USER TESTING:}

The concept was evaluated using physical paper maps laid with $3 \times 3$ grids on it. 15 people were asked about the frequent stations to which they travel e.g. their native place, work place, place where their family reside. Then they were told to locate these stations with the help of grid laid out on the map. It was found mostly everyone was able to locate these stations on the map. If the station does not exist on map, they were able to point out nearest junction or major station.
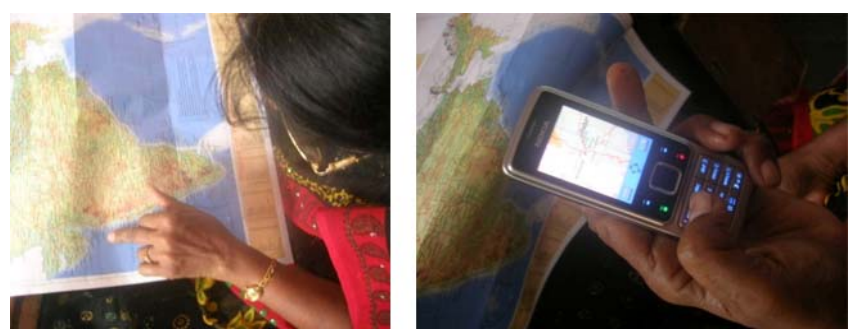

Figure 2: User testing with physical paper map and prototype build in Nokia 6300

Then they were asked about some places where they had visited in past but are not frequently visited place. Out of $15 ; 12$ could figure the required station in first 2 attempts whereas, 3 took more than 2 attempts to locate.

At the end last task for these users was to locate a station where they have never been before nor its location is known to them and which was not popular. Some hints like the state in which it is present and some major junction besides it was disclosed to help them. 11 people were able to find it whereas 4 people could not find it.

Another interesting finding which came out was semi-literate people could not enter/create or write the name of their native stations in English or their native languages comfortably; but could easily recognize their station name from already written group of similar names.

This map-based navigation was then prototyped on Nokia 6300 , which is one of the popular handset and many similar mid-range handset are widely used in India. Prototype was then tested with same users. Because of new paradigm of navigation and since, people were used to list based navigation of handset manufacturer; this map based navigation was little difficult to understand at first go. This number pad based navigation worked quite well. Also, numbers written on grid made a positive difference and it assisted users in navigation this was observed while users were trying prototype. Similar, number pad based navigation concept was successfully tested in one of the mobile phone study for illiterate "Shree Ganesha Phone" another project going on parallel in institute with Nokia[8].

But, it was found, when the users reached first or second zoom in level, then the navigation model was completely clear to them and they started using it confidently. After first use people used to confidently explore the stations. 


\section{COMPARISON OF MAP BASED WITH TEXTUAL INPUT METHOD:}

20 participants with mix of age ranging from 23-45 years, different levels of literacy were interviewed and given tasks for testing. Out of twenty 10 were semi-literates migrants from small towns, 5 were illiterates using basic range mobile phone and; the rest 5 were mobile phone savvy literates. This also resulted in different level of tech savvy nature of users. They were given tasks to enter station name using text input and by map-based method.

12 people who were new or not very well familiar to text inputting in mobile phone were able to select station quickly and easily, as compare to text inputting from first time use itself. Whereas 8 people, familiar with text inputting could enter station name fast using text inputting for first time use. But, from second time onwards map-based method was found to be faster.

It was very important to note that people who were non-tech savvy or semi-literate, very strongly preferred map-based input method over text inputting. This was because of difficulty in understanding three tap method of text inputting compared to this new map based inputting. Also, the time difference between two methods for this group of participants was comparatively high.

\section{REFINING IDEA:}

Form the user testing it came out that people were getting confused with the stations which are near the edges, outside/inside the grid. The confusion was in which cell is that station.

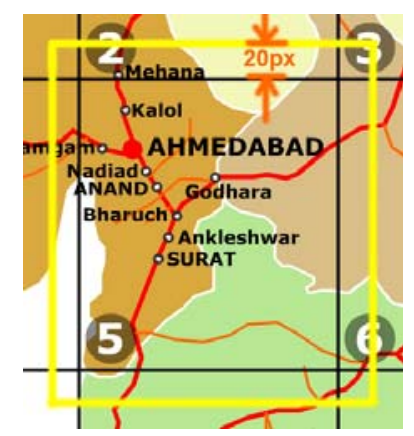

Figure 3: +20 pixel area appears in next zoom level

So, in order to avoid the confusion, these stations which were on edges would appear in next zoom level of both the adjacent cells. Hence, stations which are currently 20 pixels outside the grid would still appear inside the cell of its next zoom in level. Similarly, the stations which are 20 pixels inside the grid would appear in next adjacent cell if zoomed in. This can be explained by example illustrated in figure above.

In above case shown in figure, station Mehana is confusing, now even if it is in cell 2 it will appear in both grids 2 and 5 at next zoom in level.

\section{CONCLUSION:}

We can conclude that Map-based method for inputting Source/Destination is easier for the people who are not at all or very little familiar with text inputting on mid-range mobile phones using number pad. However for the people who know text inputting; map-based method is easier and faster than text inputting, after its first use by them. Hence it can also be said that this method works very well for all kind of users and especially well for semiliterates and non tech savvy people.

This method does not work in some cases where people do not have any idea of location of their station; however these cases are expected to be very less. The work around for this is incorporated in later combined design by giving an option to input station using text input method, this option is easily accessible from map-based option.

This new map-based method can be used for inputting in many different contexts when user has some idea of where the element would be present on the map. It can be applicable in many UI navigation ways where people we can put the elements on map and there is some correlation of finding the position of that element and; now UI can become infinite canvas for the elements spread on it. This kind of navigation can be useful for navigation and controlling Web-page Browsing on small mobile screen, Text inputting, Image viewer, Menu-system itself for phones, Stock-market status overview etc.

Also, being specific to this map based inputting for selection of source / destination, location or region it can be useful in many sectors like healthcare, governance, traffic highlights etc.

Hence, this method can make above mentioned tasks very easy and quick on extensively used midrange mobile phone with small UI real estate and; open many different service opportunities obstructed due to small size of mobile phones in developing county like India.

\section{ACKNOWLEDGEMENTS:}

We thank Prof. Aniruddha Joshi for his constant guidance throughout the project and his research work which helped a lot. Sincere thanks to Prof U. A. Athavankar, Prof. Ravi Poovaiha, and Prof. G. V. 
Sreekumar for their help. We also thank Nokia for inputs; all participants, users who provided feedback and friends from ACE and IDC for their help and support.

\section{REFERENCES:}

[1] TRAI Information Note to the Press (Release No.73/2009)

http://www.trai.gov.in/WriteReadData/trai/upload/Pr essReleases/706/pr4nov09no73.pdf

[2] Anirudha Joshi; Mobile Phones and Economic Sustainability - Perspectives from India; First International Workshop on Expressive Interactions for Sustainability and Empowerment (EISE 2009).

[3] Indian Railways Year Book (2006-2007). Ministry of Railways, Government of India. 2007. pp. 2-3. Retrieved 2008-12-23.
[4] An Analysis on the behavior of Payment Gateways during the month November - 09 http://www.irctc.co.in/\#

[5] Indian Railways - IR Station Codes http://www.indianrail.gov.in/stn_code.html

[6] Census of India, Edu. lev. by age and sex for population ageabove7,

www.censusindia.net/results/C_series/C_series_pd f/c8_india.pdf

[7] http://en.wikipedia.org/wiki/Official_lang

uages_of_India; The Languages of India.

[8] Shree Ganesha: The First Phone for Illiterate Users Nikhil Welankar, Kirti Kanitkar, Anirudha Joshi; USID 2008 Bangalore. 